\title{
Food selection by herbivores and neighbourhood effects in the evolution of plant defences
}

\author{
Pasi Rautio ${ }^{1,2}$, Ulrika A. Bergvall ${ }^{3,4}$, Juha Tuomi ${ }^{5}$, Kari Kesti ${ }^{5}$ \& Olof Leimar ${ }^{3}$ \\ 1) Tovetorp Zoological Research Station, Stockholm University, SE-640 50 Björnlunda, Sweden \\ 2) Present address: Finnish Forest Research Institute, Northern unit, Eteläranta 55, Fl-96300, \\ Rovaniemi, Finland (corresponding author's e-mail: pasi.rautio@metla.fi) \\ 3) Stockholm University, Department of Zoology, SE-106 91 Stockholm, Sweden \\ 4) Grimsö Wildlife Research Station, Department of Ecology, Swedish University of Agricultural \\ Sciences, SE-730 91 Riddarhyttan, Sweden \\ 5) Department of Biology, P.O. Box 3000, Fl-90014 University of Oulu, Finland
}

Received 1 June 2011, final version received 22 Dec. 2011, accepted 17 Jan. 2012

Rautio, P., Bergvall, U. A., Tuomi, J., Kesti, K. \& Leimar, O. 2012: Food selection by herbivores and neighbourhood effects in the evolution of plant defences. - Ann. Zool. Fennici 49: 45-57.

\begin{abstract}
A number of studies have reported how neighbouring plants may influence herbivory on palatable or unpalatable plants. Such neighbourhood effects can have important evolutionary consequences as they may either promote the evolutionary stability of plant defences or, alternatively, select against the fixation of plant defences and instead promote a stable polymorphism of palatable and unpalatable plants. These consequences depend on whether the difference in herbivore damage between unpalatable and palatable plants is smaller or, alternatively, greater when the neighbours are unpalatable instead of palatable. Such relations can arise when the neighbourhood effects are non-parallel among palatable and unpalatable plants. We outline two basic situations of non-parallel neighbourhood effects and illustrate how they can come about. A detailed dissection of these interactions reveals that there are several qualitatively distinct mechanisms that promote either evolutionary stability of plant defences or alternatively polymorphism. Our classification of mechanisms can be used to clarify and explain observations obtained in the field of plant-herbivore interactions and predator-prey interactions, both at the population and the community level.
\end{abstract}

\section{Introduction}

Through selective foraging, herbivores can influence the composition of plant populations and thus contribute to the ecology and evolution of plant species (Bryant et al. 1989, Vourc'h et al. 2002, O'Reilly-Wabstra et al. 2004, Andrew et al. 2007, Bailey et al. 2007). From the point of view of an individual plant, herbivory influences fitness by reducing growth or reproduction and increasing mortality (e.g. Olff et al. 1999). Plants are able to avoid herbivory-mediated fitness loss by different defence mechanisms (toxic compounds, thorns, spines, etc.), which can act as repellents and, at least to some extent, decrease the adverse effects of herbivory (Palo \& Robbins 1991). Classical plant defence theories have assumed that the evolution of defences depends on the production and maintenance costs of the defences and, on the other hand, on the ben- 
efit that the plant gains from its own defence investment (Rhoades 1979). There are, however, several empirical studies which have indicated that herbivore attack and consumption rates are dependent not only on a plant's own defence traits, but also on the defence traits of its neighbours (e.g. Tahvanainen \& Root 1972, Atsatt \& O’Dowd 1976, Hjältén et al. 1993, Hambäck et al. 2000; see also Agrawal et al. 2006 for a review). These studies have shown that target species have an advantage (or disadvantage) when associating with either more palatable or less palatable heterospecifics.

The influence of neighbours on the attack rate of herbivores on a target plant depends on the spatial scale of herbivore decisions (Milchunas \& Noy-Meir 2002). Since herbivores can be selective or non-selective on several spatial scales (e.g. between or within plant patches) this can give rise to several different associational effects (Bergvall et al. 2006, 2008, Rautio et al. 2008). Traditionally, these (associational) neighbourhood effects have been divided into associational defence (syn. in literature associational resistance, associational plant refuges, plant defence guilds, see e.g. Tahvanainen \& Root 1972, Atsatt \& O'Dowd 1976, McNaughton 1978, Pfister \& Hay 1988, Hambäck et al. 2000, Bergvall et al. 2008) and associational susceptibility (syn. in literature associational damage, shared doom, see e.g. Thomas 1986, Brown \& Ewel 1987, Hjältén et al. 1993, Wahl \& Hay 1995, Karban 1997, Rautio et al. 2008). Associational defence refers to a situation where palatable plants gain protection from their unpalatable neighbours whereas associational susceptibility refers to a situation when an unpalatable plant is consumed more when associated with palatable neighbours. Both associational defence and associational susceptibility are outcomes of herbivores being selective between patches of food plants and relatively unselective within patches.

Heterospecific associational effects can promote the coexistence of palatable and unpalatable plant species (Tahvanainen \& Root 1972, Augner et al. 1991). Similar neighbourhood effects can also take place between conspecific neighbours (i.e. individuals of the same species with different levels of defence). For instance, Tuomi and Augner (1993) suggested that asso- ciational defence can promote a stable polymorphism where both palatable and unpalatable plants coexist in a population. This provides an evolutionary perspective on "defence guilds" and associational defence (cf. Atsatt \& O'Dowd 1976, Hay 1986, Hunter \& Aarssen 1988, Pfister \& Hay 1988). Tuomi et al. (1999: p. 80) emphasized that in the case of stable polymorphism, "the undefended and defended plants do not coexist for any mutual benefit", but instead the situation resembles a Prisoner's dilemma game (e.g. Axelrod 1984), where "defended plants act as helpers by reducing the risk of herbivore attack, while undefended plants are the cheaters which benefit from the reduced attack rate without any cost of defence". Consequently, these kinds of associational effects tend to counteract the evolution of plant defences, since it would be advantageous for a defended plant to reduce its costly defence investment in situations where it is already well protected by the defence traits of its neighbours (Tuomi et al. 1994, 1999, Leimar \& Tuomi 1998).

Quite different associational effects will come about if herbivores instead are more selective within a patch than between patches. One factor promoting within-patch selectivity could be that the defence traits have signal value for the herbivores, so that they could easily distinguish defended and undefended plants from each other (Augner 1994, Tuomi et al. 1994, 1996). In a patchy population, palatable plants are then less likely to gain protection by associating with unpalatable plants. In some cases, this could lead to synergistic selection (sensu Maynard Smith 1998), since if unpalatable plants are eaten less when associated with other unpalatable plants than when their neighbours are palatable, they are gaining benefits from each other (cf. the traditional definition of associational susceptibility that implicitly assumes that unpalatable plants do better among other unpalatables, since they do worse among palatables). Tuomi and Augner (1993) suggested that such synergistic benefits might promote the evolution of plant defences in situations where palatable plants do not gain any significant associational resistance from their unpalatable neighbours. However, if palatable plants gain associational benefits from unpalatable neighbours, even strong synergism 
may fail to enhance the evolution of defences if it is nullified by equally strong or even stronger associational benefits for palatable plants (Tuomi \& Augner 1993, Leimar \& Tuomi 1998; see also Mappes et al. 1999).

These analyses emphasize that, in evolutionary contexts, the consequences of neighbourhood effects depend on the effects of neighbour interactions on the fitness of both palatable and unpalatable plants. In other words, we need to know how well palatable and unpalatable plants perform when their neighbours are palatable or, alternatively, unpalatable. Generally, however, the neighbourhood effects are separately defined for palatable plants (associational defence) and for unpalatable plants (associational susceptibility) without any reference to the performance of the other plant type. We, therefore, interpret the definitions of these two types of neighbour effects to implicitly assume that the other plant phenotype is not affected by the neighbourhood. Furthermore, the division of the neighbourhood effects into the two types (associational defence and susceptibility) may overly simplify the mechanisms that are actually behind the evolution of plant defences. For instance, it is not at all obvious whether associational susceptibility and synergism, as described above, refer to the same kind of neighbour interactions or whether they in fact are consequences of qualitatively different types of neighbour interactions. To shed light on such questions, we have attempted to outline possible neighbour interactions that promote the evolutionary stability of defence or, alternatively, can select against the fixation of defence and instead favour a polymorphism.

To focus sharply on neighbourhood effects, we mainly neglect other mechanisms like the costs of defences and the compensatory growth after herbivore damage. In general, however, the nature and shape of the trade-off between the cost of defence and an increased resistance to herbivore attack will be important (de Mazancourt \& Dieckmann 2004), both for the overall level of defence and for defence variability. For instance, if the overall rate of attack on a population depends on the population-average defence level, certain trade-offs can give rise to a polymorphism in defences (cf. Svennungsen \& Holen 2007). Interestingly the overall defence level links neighbourhood effects also to Müllerian mimicry, since in Müllerian mimicry the driving force is in fact monomorphism, i.e. the tendency towards the common warning signal (Ihalainen et al. 2007). We also bypass here herbivory-mediated compensatory growth that can even result in fitness benefits compared to undamaged plants (e.g. Huhta et al. 2000 and references therein). However, in order to clarify mechanisms behind associational neighbourhood effects our analysis here deals only with the neighbourhood effects per se and their influence on the evolution of plant defences, over and above other effects that may also have evolutionary consequences.

In this conceptual development, we aim to reveal the underlying mechanisms behind three possible scenarios of how the neighbourhood can influence the evolution of plant defences: (A) no neighbourhood-mediated selection for defence, (B) neighbourhood-mediated selection for defence, and (C) neighbourhood-mediated selection against defence.

\section{Material and methods}

We describe the fitness consequences of herbivory in terms of biomass loss (consumption) of palatable and unpalatable plants in different neighbourhoods (Fig. 1). First, in Fig. 2 (row 1) we depict the three possible effects (columns A, $\mathrm{B}$ and $\mathrm{C}$ ) that neighbours can have on the evolution of plant defences. These effects are described (in row 1) as herbivore consumption related to the non-defended (i.e. palatable) plants. Hence, the relative consumption of palatable plants is 1 and that of unpalatables less than 1 . In rows 2-4, we show the possible situations, in terms of (the logarithm) of absolute consumption, that can produce the effects in row 1 (note that a given difference in log consumption correspond to a given relative consumption). Second, we compare group-growing plants (Fig. 1a and b) to the "solitary" plants, or more precisely to plants growing in an environment without clear patch structure and free from any neighbourhood effects (Fig. 1c and d), in order to make a further subdivision of possible mechanisms (Fig. 3; see also Tahvanainen \& Root 1972, Mappes et al. 1999). In this 

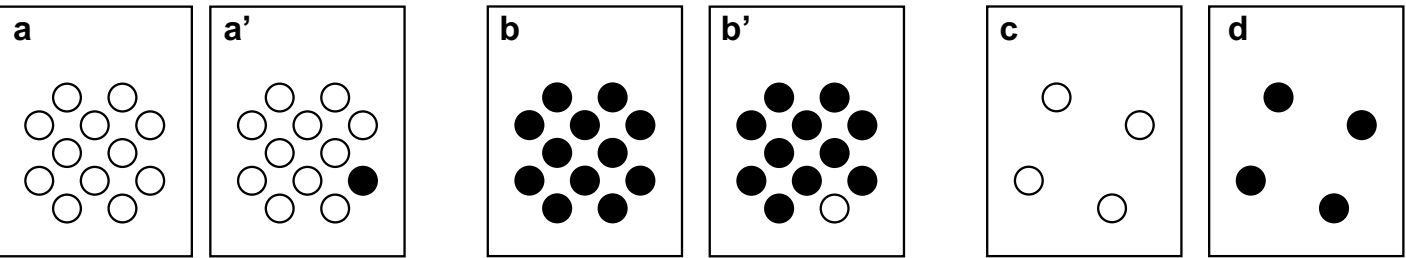

Fig. 1. Palatable $(\bigcirc)$ and unpalatable $(\mathbf{O})$ plants growing in patches (a and $\mathbf{b}$ ) or alone without clear patchy population structure (c and $\mathbf{d}$ ). We assume that for a palatable plant, the average consumption in cases a and $\mathbf{a}$ ', and similarly for an unpalatable plant in cases $\mathbf{b}$ and b', is not different. Hence in Figs. 2 and 3, consumption rates are given for patch types a' and b' only. In addition, in Fig. 3 consumption rates are given for solitary palatable and solitary unpalatable plants (c and $\mathbf{d}$, respectively) assuming that consumption of these plants is not affected by the neighbourhood. Note that in situations where there are only two plants in a patch, a' and b' refer to the same patch structure, i.e. with one palatable and one unpalatable plant.

A

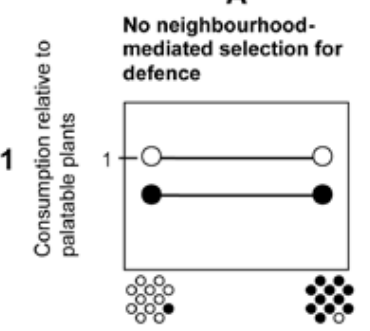

No neighbourhood effects

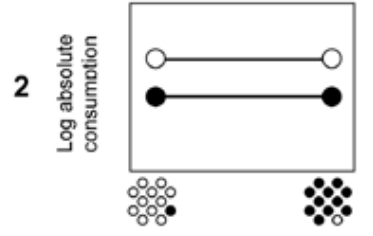

Additive neighbour effects

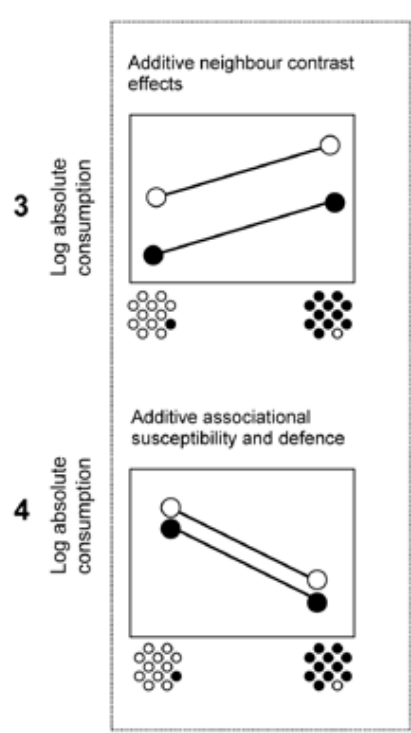

B

Neighbourhoodmediated selection for defence
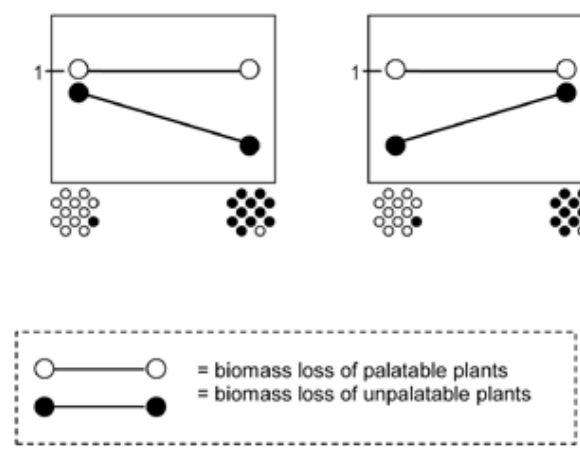

Promoting evolutionary stability of defence

Neighbour contrast susceptibility or Dilution of consumption risk

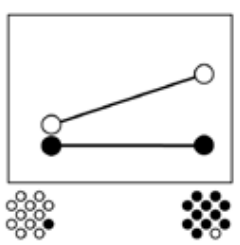

Associational susceptibility or Group synergism

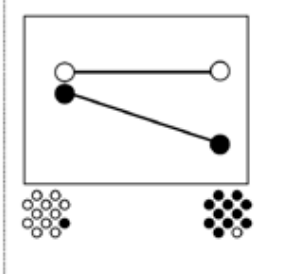

C mediated selection

\section{Neighbourhood-} against defence

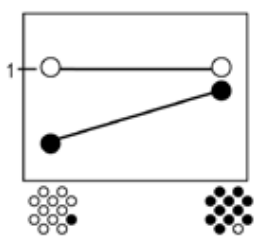

Fig. 2. Three possible effects neighbours can have on the evolution of plant defences: (A) no neighbourhood-mediated effects, (B) neighbourhood-mediated selection for defences, and (C) neighbourhood-mediated selection against defences when the focal plants are growing in a neighbourhood of mainly non-defended (O) or defended (๑) plants (presented on $x$-axis). In row 1 the consumption of palatable (i.e. non-defended or less defended) and unpalatable (i.e. defended) plants is related to the consumption of palatable plants, thus the value for palatable plants is 1 and for unpalatable plants less than 1 . In rows 2-4 the situations, in terms of absolute consumption (on logarithmic scale), producing the effects in row 1 are described. 

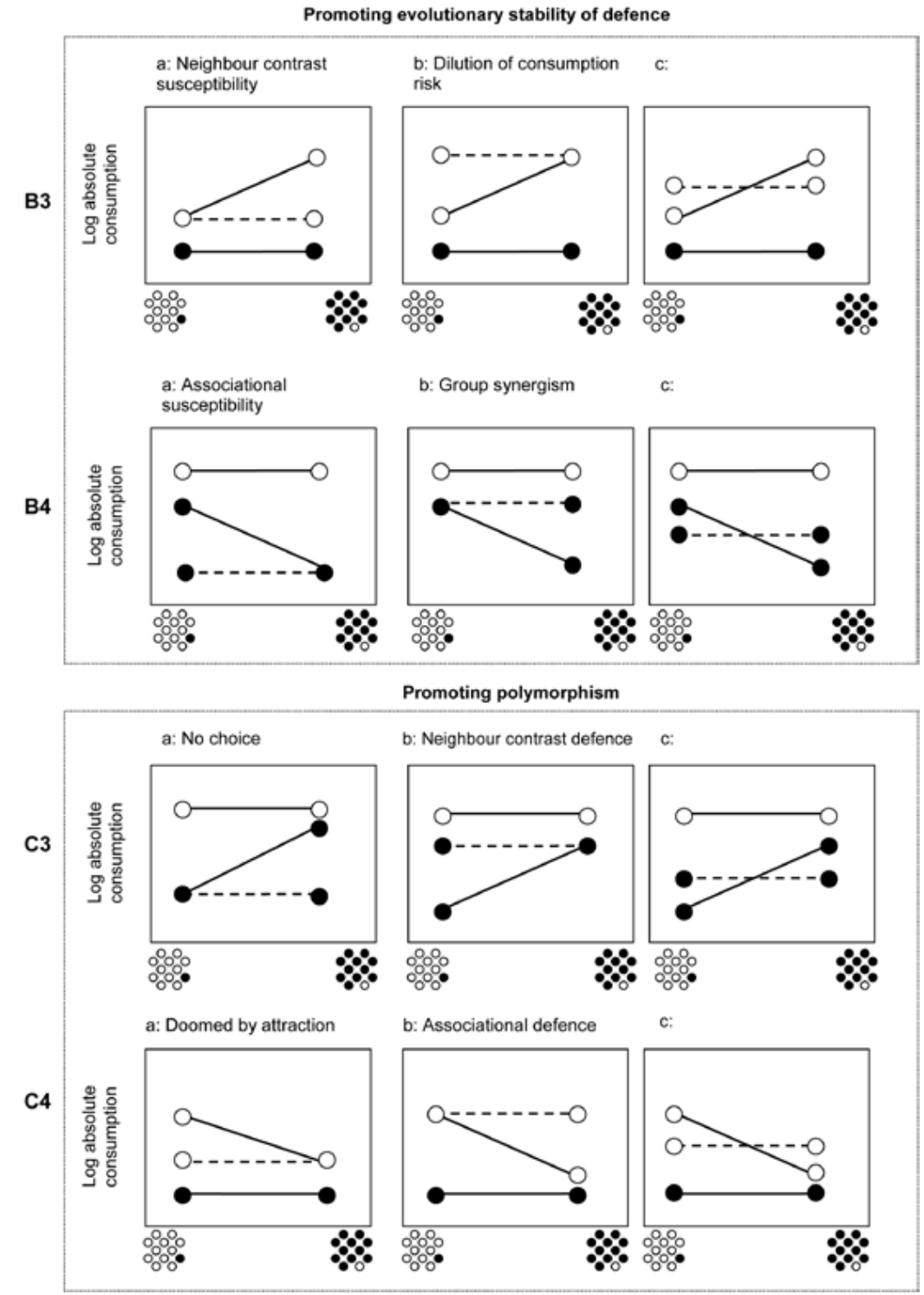

Fig. 3. Subdivision of the associative effects (B3, B4, C3 and C4) shown in Fig. 2 when the absolute consumption of palatable $\left(\mathrm{O}_{-} \mathrm{O}\right)$ and unpalatable $(-\mathbf{0})$ plants growing either in mainly non-defended or defended neighbourhoods is presented along with the consumption of a palatable plant $(\bigcirc--\bigcirc)$ or an unpalatable plant growing alone (---). All four effects (B3, B4, C3 and C4) are further divided into three separate effects (a, b and c): B3a: susceptibility of palatable plants increases in the neighbourhood of unpalatable plants, for instance because the herbivore preference for a food plant depends on the relative difference of defence chemical concentrations between available plants; B3b: a given consumption rate of a single herbivore or a given number of herbivores is either concentrated on a single palatable plant or a group of palatable plants such that consumption per plant is lower in the group; B4a: unpalatable plants are more often attacked by herbivores in the neighbourhood of palatable plants; B4b: unpalatable plants growing in a group experience lower rate of consumption than solitary unpalatable plants due to more effective repellence of defence in the group; C3a: herbivores attacking an unpalatable plant are repelled and they will attack the nearest neighbour which is also an unpalatable plant; $\mathbf{C} \mathbf{3 b}$ : an unpalatable plant is even less preferred in the neighbourhood of palatable plants; C4a: palatable plants growing together are doomed to experience higher consumption as compared with solitary palatable plants, and those growing in the neighbourhood of unpalatable plants because herbivores aggregate in areas with many palatable plants; C4b: palatable plants gain protection from their unpalatable neighbours. 
way, the situations where neighbourhood effects promote the evolutionary stability of defence (Fig. 2 cases B3 and B4) and where they promote polymorphism (Fig. 2 cases $\mathrm{C} 3$ and $\mathrm{C} 4$ ) can be further divided into three separate situations $(\mathrm{a}, \mathrm{b}$ and $\mathrm{c}$ in Fig. 3).

In our analyses, we assumed that the starting point (biomass) before the herbivore consumption is the same for all target plants, hence if equal amount of biomass is lost by herbivore consumption the biomass left after the consumption is equal. Further, we assumed that the biomass that is left after the herbivore consumption is correlated with fitness; hence if the biomass of target plants in two different neighbourhoods after the herbivore consumption is equal also the fitness is equal. For each scenario, we present examples of evidence in the literature if we found such studies (in most cases for heterospecific interactions, i.e. neighbourhoods consisting of different plant species). In case we found evidence for a scenario shown in Fig. 3 (i.e. in a study where there was comparison to solitary plants/prey), we specifically mention this. If plant-herbivore studies did not provide such evidence, we present an example of predator-prey interactions in order to show that such a scheme exists as an ecological phenomenon.

\section{Results and discussion}

\section{A: No neighbourhood mediated selection for defence}

The neighbourhood does not create any pressure for the evolution of defence when the defence level of defended plants (unpalatable or less palatable) yields the same relative benefit when compared with that of palatable plants irrespective of the neighbourhood (Fig. 2: column A row 1). This can be a result of three different situations when one considers the (log) absolute consumption of a given type of plant. First, the neighbourhood may have no effect on the absolute consumption rates on the plant types (Fig. 2: A2). Second, and perhaps unrealistically, both types are eaten more in the defended neighbourhood, but the neighbourhood has no effect on the benefit of defended plants (Fig. 2: A3).
Third, both types are eaten less in a defended neighbourhood, but the benefit of the defended plants is the same (Fig. 2: A4). In the cases of "additive neighbour contrast effects" (Fig. 2: A3) and "additive associational susceptibility and defence" (Fig. 2: A4) neither the unpalatable nor palatable plants obtain an advantage by associating with the opposite or the similar kind and, hence, these effects can also be labelled as "parallel neighbour effects". Because the allocation to defence produces the same degree of advantage despite the neighbourhood, the neighbours are not the driving force behind the evolution of defences.

\section{B: Neighbourhood mediated selection for defence}

Evolutionarily different outcome will come about when defended plants in the defended neighbourhood are eaten less than would be expected on the basis of the consumption in the undefended neighbourhood. In other words, since the consumption of defended plants is lower than that of non-defended, and this difference gets larger in defended neighbourhood, this promotes evolutionary stability of defence (Fig. 2: B1). This, in turn, can be an outcome of two different situations when comparing (log) absolute consumption rates of group-growing plants (Fig. 2: B3 and B4), which both can be considered cases that promote the evolutionary stability of defences. However, when one compares the consumption also to the consumption of solitarily-growing plants both cases can be further divided into three different subcases (Fig. 3: B3a-c and B4a-c).

First, when the herbivore is selective within a patch consisting of mainly unpalatable plants, the contrast between unpalatable and palatable plants almost certainly disfavours palatable plants (Fig. 2: B3). This will lead to higher consumption of palatable plants in a defended neighbourhood than would be expected on the basis of the consumption in a non-defended neighbourhood. However, if the group-growing palatable plants are further compared with solitary palatable plants (cf. Fig. 1c) we end up in situations B3a-c in Fig. 3. When group-growing 
palatable plants are eaten more in defended than in non-defended neighbourhoods, and in the defended neighbourhood more than solitary plants we refer to this as "neighbour contrast susceptibility" (Fig. 3: B3a), because the driving force is the contrast in palatability or degree of defence (Bergvall et al. 2006). Hence, the palatable plant is more susceptible to herbivory through the contrast between itself and its less palatable neighbours. If, on the other hand, the group-growing palatable plants, when growing among the same kind, are on average eaten less than solitary palatable plants (Fig. 3: B3b) we consider this a case of "dilution of consumption risk". This is because when palatable plants occur together, the amount of high quality food is higher and the consequent risk of herbivory is most likely smaller per individual plant than if only a solitary plant is available for the herbivore. Both the neighbourhood contrast susceptibility and dilution of consumption risk can also be operating at the same time (Fig. 3: B3c).

Second, "associational susceptibility" by the traditional definition means that an unpalatable plant is eaten more in a patch consisting of mainly palatable plants, meaning that unpalatable plants get a benefit by associating with other unpalatable plants. The presupposition for this is that herbivores are selective between patches but relatively unselective within patches. We argue, however, that this definition is justified only if unpalatable plants growing in the nondefended neighbourhood are eaten more than solitary unpalatable plants (Fig. 3: B4a). If they, on the other hand, are eaten less than solitary plants when associated with their own kind (Fig. 3: B4b) we consider this "group synergism" (cf. Mappes et al. 1999). We want to emphasise that this is not a mere dilution effect because a solitary unpalatable plant and unpalatable plant(s) among palatable plants experience equal consumption. Again, associational susceptibility and group synergism can act simultaneously (Fig. 3: B4c). According to Tuomi and Augner (1993) and Leimar and Tuomi (1998), these neighbourhood effects can promote the evolution of constitutive plant defences. They may, however, be important also in promoting the evolution of systemic inducible defences which can spread from a plant unit to another. There may well appear e.g. synergism among branches within a tree, but synergism among physically separate plants could, at least in theory, even promote the spread of defence induction from an attacked plant to unrelated, unattacked neighbours (Järemo et al . 1999; for three-trophic system, see Kobayashi \& Yamamura 2003, 2007).

\section{Examples of evidence}

The term "neighbour contrast susceptibility" (introduced by Bergvall et al. 2006) originates from the observations by Bergvall and Leimar (2005) in which the defence level (tannin concentration) of food was either low or high. If the contrast between low and high defence was great (fivefold difference), the consumption of the low defence-level food by mammalian herbivores (fallow deer, Dama dama) was significantly higher than if the contrast between low and high defence-level food was smaller (twofold difference). Further, the deer searched through more food items if the contrast was greater. Hence, the palatable plant is more susceptible to herbivory through the contrast between itself and its less palatable neighbours. The behavioural process behind this selection is explained by positive consummatory contrast, which has been found in e.g. fallow deer that consumed more low-tannin food when it was presented after high-tannin food as compared with the situation in which only low-tannin food was offered (Bergvall \& Balogh 2009).

Even though in plant-herbivore systems the idea of "dilution of consumption risk" has not been widely documented (though see Karban et al. 1989, Ericsson et al. 2001), risk dilution (in some cases labelled safety-in-numbers) has been widely studied in predator-prey interactions (e.g. Connell 2000 and references therein). As an example, schooling of fish prey is reported to reduce predation risk against some fish predators (reduced per capita attack rate, i.e. speaking for dilution of consumption risk) but at the same time schooling might increase the risk against other fish predators, cf. doomed by attraction (Connell 2000, Connell \& Gillanders 1997). In plant-herbivory interactions synchronous reproduction and predation satiation is a classical 
example of risk dilution in relation to seed predation (e.g. Janzen 1971, Herrera et al. 1998, Schnurr et al. 2002).

"Associational susceptibility" has been observed in several plant-herbivore systems, though generally when studying heterospecifics (e.g. Thomas 1986, Brown \& Ewel 1987, Hjältén et al. 1993, Wahl \& Hay 1995, Karban 1997). However, Rautio et al. (2008) mimicked conspecific neighbourhood environment in an artificial world setup, using a large mammal herbivore as a consumer, and observed that when unpalatable food occurred among the palatable food, it was more consumed than among other unpalatable feeds, i.e. supporting the traditional definition of associational susceptibility. Karez et al. (2000) found that isopod (Idotea granulosa) consumed more brown seaweed (Fucus vesiculosus) when it had an epiphyte (Elachista fucicola) as compared with when it was free of the epiphyte. Karez et al. (2000) concluded that brown seaweed was co-consumed due to herbivore attraction by the epiphyte.

We are not aware of studies examining "group synergism" in plants in accordance with the definition described here (i.e. with comparison to solitary plants: Fig. 3: B4b), but examples of other ecological system exists. When studying the evolution of aposematism Mappes et al. (1999) found synergistic benefits shared by aposematic individuals. Mappes et al. (1999) let birds select artificially aposematic mealworms (treated with aqueous chloroquine and painted with yellow/black dots) that were offered either solitarily or in groups with other aposematic prey or palatable prey. Aposematic prey had lower mortality (were eaten less) when offered with other aposematic prey than solitarily-living prey or aposematic prey living together with palatable prey (cf. Fig. 3: B4b).

\section{C: Neighbourhood mediated selection against defence}

The situation where unpalatable plants obtain an advantage by associating with palatable plants is favourable for the invasion of unpalatable plants in a population of palatable plants, but not for the evolutionary stability of plant defences, since the relative consumption difference is greater in the non-defended neighbourhood (Fig. 2: C1). In other words, since the benefit from defence (in relation to non-defended) gets smaller when there are more defended plants in neighbourhood, this promotes coexistence of both types. Again this outcome can come about through two different situations with regard to the (log) absolute consumption. Because these mechanisms will lead to situations in which both unpalatable and palatable (Fig. 2: C3 and C4, respectively) plants get an advantage by associating with the opposite kind, we consider them promoting polymorphism.

First, when the herbivore is selective within a patch of mainly palatable plants (non-defended neighbourhood), the unpalatable plants could be less eaten than expected from a defended neighbourhood (Fig. 2: C3). When there is a disadvantage for group-growing unpalatable plants to associate with their own kind as compared with the situation for unpalatable solitary plants (Fig. 3: C3a), we consider this a case of "no choice" since after the few palatable plants available have been eaten in a patch consisting mainly of unpalatable plants there is nothing else to eat than defended plants. If such shared accidents occur among unpalatable plants, one could expect that palatable plants also experience higher consumption in the neighbourhood of unpalatable plants (cf. Fig. 3: B3a). On the other hand, for the situations where solitary unpalatable plants are eaten more than in the non-defended neighbourhood we suggest the term "neighbour contrast defence" (Fig. 3: C3b), since the contrast perceived by the herbivore enhances the protective effects of the defence (cf. the previous discussion of the situation of Fig. 3: B3a; Bergvall et al. 2006).

Second, the situation in which the herbivore makes a foraging decision to leave a patch of mainly unpalatable plants can lead to associational advantage for palatable plants in that patch, a situation commonly referred to as "associational defence" (Fig. 2: C4). However, we argue that this definition is justified only if palatable plants growing in the defended neighbourhood are eaten less than solitary palatable plants (Fig. 3: C4b). If they, on the other hand, are eaten more than solitary plants when asso- 
ciated with their own kind (Fig. 3: C4a), we consider this "doomed by attraction" as palatable plants growing together are hit harder when, for example, groups of grazers ignore solitary plants (or poor patches) and aim for more attractive (richer) patches and concentrate their foraging on this kind of patches. Again "associational defence" and "doomed by attraction" can act simultaneously (Fig. 3: C4c). Finally, note that, even though these neighbour effects are favourable for the invasion of rare unpalatable plants, they can counteract the evolutionary stability of plant defences by favouring palatable plants in a population dominated by unpalatable plants.

\section{Examples of evidence}

We are not aware of studies supporting the concept of "no choice" by comparing solitarily- and group-growing unpalatable plants (see Fig. 3: C3a). However, authors' own observations of a group of fallow deer being reluctant to change from a patch of mainly high-tannin food to a "better patch" having more low-tannin food gives support to the idea of "no choice". In that study the deer presumably considered the alternative patch to be too far away (the deer switched to the other patch if it was nearby). The outcome was that the deer consumed more or less all the low-tannin food in the patch of mainly high-tannin food and additionally much more high-tannin food than if they could choose between the two nearby patches.

The concept of "neighbour contrast defence" was introduced by Bergvall et al. (2006) to highlight the mechanism in herbivores' food selection where the contrast between the amount of defence substance allocated by the defended plant $v s$. the non-defended plant influences the herbivore attack (cf. the previous discussion about "neighbour contrast susceptibility"). There are also field observations of browsing patterns supporting this kind of neighbour-mediated effect (Miranda et al. 2011).

Evidence for "associational defence" has been reported by e.g. Tahvanainen and Root (1972), who noticed that a flea beetle preferred the collard leaf that was kept alone over the collard leaf that was offered with a tomato or ragweed (or just odour of these). To our knowledge, Tahvanainen and Root (1972) presented the only evidence in the context of plant-herbivory interactions for "associational defence" as depicetd in Fig. 3.

"Doomed by attraction" was observed in several studies that examined the effect of food density on the herbivore selectivity. For example, Distell et al. (1995) noticed that the intake rate of cattle was positively related to the density of ryegrass in the food patches, Dumont et al. (2000) found that plant species that sheep were searching for were less exploited when evenly dispersed than when they were aggregated, and Ball and Dahlgren (2002) reported that browsing pressure by moose increased with pine density. In predator-prey systems e.g. Connell and Gillanders (1997) have shown that the mortality rates of aggregating fish are greater than solitary species of the same genus.

\section{Interface with other kinds of plant-plant interactions and with herbivore behaviour}

The neighbourhood effects described above bear many similarities to some other species interactions schemes described in the literature. Apparent competition refers to a negative effect of a plant species (or a type) on the performance of another species as mediated by herbivore behaviour and densities (Holt 1977, Chaneton $\&$ Bonsall 2000). Consequently, neighbour contrast susceptibility and associational susceptibility would enhance apparent competition between palatable and unpalatable plants, because each type would suffer a fitness decrement as compared to solitary plants when the neighbours of the other plant type are present (Table 1). Rand (2003) noticed the connection between associational susceptibility and apparent competition when the plant suffers more intense herbivory in the presence of more palatable neighbours. However, neighbour contrast susceptibility has a similar effect on palatable plants in the presence of less palatable neighbours (Table 1). Therefore, neighbour effects as outlined here can also be important in identifying potential mechanisms which can lead to apparent competition between plants that differ in herbivore resistance. 
The within-patch selectivity by herbivores is likely to be enhanced if the defence traits of plants have a signal value for herbivores. Existence of such a signal creates an opportunity to mimic that signal, which links neighbourhood effects to Batesian mimicry. Augner and Bernays (1998) have shown that even an imperfect mimic can invade a population of signalling-defended plants in case the "avoidance sequence" of a herbivore is long enough, i.e. it avoids a signalling plant long enough after attacking a defended plant. In Müllerian mimicry, variation in the defence level can lead to a situation where less defended co-mimics dilute the effect of defence of better defended co-mimics (Speed et al. 2000). This in turn could lead to higher consumption of better defended mimics in a patch of less defended co-mimics, i.e. to same outcome as "associational susceptibility" or "group synergism" here.

\section{Things to consider in future studies}

It should be noted that, although we have dis- cussed neighbourhood effects in the context of a patchy population structure of plants, this what is shown in Figs. 2 and 3 does not necessarily presume a patchy population structure. Instead, when the neighbourhood effects are mediated by the herbivores' behaviour, the interacting plants may grow close to each other or, alternatively, they may grow farther away but the experience of the herbivore on one of the plant types has fitness consequences for the other. Accordingly, it might be useful to separate "group synergism", where the synergistic fitness effects are restricted within a physically distinct patch of plants, and more general "synergism" where the herbivore generalizes plant quality characteristics from an earlier attacked plant to another regardless whether the plants happen to grow in the same patch or in separate patches.

While there can be practical difficulties to unambiguously include "solitary plants" in experimental designs where the food plant selection of herbivores can be frequency-dependent, it would be important to know the performance of solitary palatable and unpalatable plants. This does not only concern the possible patterns

Table 1. Evolutionary (fitness) advantage/disadvantage of defended (unpalatable) and non-defended (palatable) plants under different associational neighbourhood effects based on the comparison of group growing vs. solitary growing plants (cf. Fig. 3). '+': fitness of group-growing plants is higher than solitary plants (group-growing plants eaten less than solitary), '-': fitness of group-growing is lower than solitary plants (group-growing plants eaten more than solitary), and '=': fitness of group-growing plants equal to solitary plants (both equally eaten). Associational effects under B3 and B4 are promoting evolutionary stability of defence, and those under C3 and C4 are promoting polymorphism. For abbreviations see Fig. 3.

\begin{tabular}{ccccc}
\multicolumn{2}{c}{ Palatable plants } & & \multicolumn{2}{c}{ Unpalatable plants } \\
\cline { 1 - 1 } \cline { 5 - 6 } $\begin{array}{c}\text { Among } \\
\text { palatables }\end{array}$ & $\begin{array}{c}\text { Among } \\
\text { unpalatables }\end{array}$ & & $\begin{array}{c}\text { Among } \\
\text { palatables }\end{array}$ & $\begin{array}{c}\text { Among } \\
\text { unpalatables }\end{array}$
\end{tabular}

B3

a: Neighbour contrast susceptibility

b: Dilution of consumption risk

$c: a+b$

B4

a: Associational susceptibility

b: Group synergism

$c: a+b$

C3

a: No choice

b: Neighbour contrast defence

c: $a+b$

C4

a: Doomed by attraction

b: Associational defence

c: $a+b$

$\begin{array}{ll}= & - \\ + & = \\ + & -\end{array}$

C: + a 
shown in Fig. 3, but is also useful in order to know how much neighbourhood effects modify plant performance in relation to the solitary plants. In fact, when establishing the concept of "associational resistance", Tahvanainen and Root (1972) included also a comparison of solitary and group growing plants. It can well be that the significance of neighbourhood effects is rather limited compared to the benefits and costs that the defensive traits of the solitary plants experience. For instance, it has been argued that synergism may have a relatively small effect on the evolution of plant defences in situations where the unpalatable plants are already well defended in terms of their own defensive traits (Tuomi \& Augner 1993, Leimar \& Tuomi 1998; for an empirical case of unpalatable aposematic and palatable cryptic larvae, see Mappes et al. 1999). In principle, "solitary plant" refers to a situation in which plant fitness is neither affected by the neighbours nor by the earlier experiences of the herbivores. If the herbivore's mechanism of generalization over food plant quality does not presume physical vicinity of the host plants, the rate of consumption of a solitary plant could be determined as the consumption rate of a plant which is the first choice of an inexperienced naïve herbivore and when this choice is not affected by the neighbourhood at all. If one cannot in practice determine consumption of a "solitary plant", it may still be possible to evaluate the neighbourhood effects at the level shown in Fig. 2, although the alternative mechanisms depicted in Fig. 3 remain unknown. Even in such a case, it is important to be aware that the neighbourhood effects in Fig. 2 can in fact result from different kinds of neighbour interactions.

We wish to highlight that a large part of the theoretical basis behind associational neighbourhood effects can be adapted from related work as, for example, some of the fitness interactions between the neighbours are qualitatively very similar to those modelled in the study of the evolution of co-operation (e.g. Maynard Smith 1998) although the plant interactions do not include "co-operative behaviour" in the strict sense. However, as pointed out by Maynard Smith (1988; see also Tuomi et al. 1999), a sessile life-style as such is not an obstacle for the evolution of co-operation because it is not "high intelligence" that is needed, but rather the presence of traits which mediate fitness interactions between neighbours. In fact, Maynard Smith (1988: p. 120) specifically suggested that "even plants could evolve co-operation, given synergistic fitness interactions".

\section{Acknowledgements}

JT and PR were financially supported by the Academy of Finland (projects 213235 and 80486) and OL was supported by the Swedish Research Council (project 621-2010-5437). We thank two anonymous referees for their comments.

\section{References}

Agrawal, A. A., Lau, J. S. \& Hampäck, P. A. 2006: Community heterogeneity and the evolution of interactions between plants and insect herbivores. - Quarterly Review of Biology 81: 349-376.

Andrew, R. L., Peakal, R., Wallis, I. A. \& Foley, W. J. 2007: Spatial distribution of defence chemicals and markers and the maintenance of chemical variation. - Ecology 88: 716-728.

Atsatt, P. R. \& O’Dowd, D. J. 1976: Plant defence guilds. Science 193: 24-29.

Augner, M. 1994: Should a plant always signal its defence against herbivores? - Oikos 70: 322-332.

Augner, M., Fagerström, T. \& Tuomi, J. 1991: Competition, defense and games between plants. - Behavioral Ecology and Sociobiology 29: 231-234.

Augner, M. \& Bernays, E. A. 1998: Plant defence signals and Batesian mimicry. - Evolutionary Ecology 12: 667-679.

Axelrod, R. 1984: The evolution of co-operation. - Peguin books, London.

Bailey, J. K., Shweitzer, J. A., Rehill, B. J., Irschick, D. J., Whitham, D. G. \& Lindroth, R. L. 2007: Rapid shifts in the chemical composition of aspen forests: and introduced herbivore as an agent of natural selection. - Biological Invasions 9: 715-722.

Ball, J. P. \& Dahlgren, J. 2002: Browsing damage on pine (Pinus sylvestris and P. contorta) by a migrating moose (Alces alces) population in winter: relation to habitat composition and road barriers. - Scandinavian Journal of Forest Research 17: 427-435.

Bergvall, U. A. \& Balogh, A. C. V. 2009: Consummatory simultaneous positive and negative contrast in fallow deer: implications for selectivity. - Mammalian Biology 74: 236-239.

Bergvall, U. A. \& Leimar, O. 2005: The role of plant secondary compounds and the frequency of food types for food choice by mammalian herbivores. - Ecology 86: 2450-2460.

Bergvall, U. A., Rautio, P., Kesti, K., Tuomi, J. \& Leimar, O. 2006: Associational effects of plant defences in relation 
to within- and between-patch food choice by a mammal herbivore: neighbour contrast susceptibility and defence. - Oecologia 147: 253-260.

Bergvall, U. A., Rautio, P., Sirén, H., Tuomi, J. \& Leimar, O. 2008: The effect of spatial scale on plant associational defences against mammalian herbivores. - Écoscience 15: 343-348.

Brown, B. J. \& Ewel, J. J. 1987: Herbivory in complex and simple tropical successional ecosystems. - Ecology 68: 108-116.

Bryant, J. P., Tahvanainen, J., Sulkinoja, M., Julkunen-Tiitto, R., Reichardt, R. P. \& Green, T. 1989: Biogeographical evidence for the evolution of chemical defense by boreal birch and willow against mammalian browsing. - American Naturalist 134: 20-34

Chaneton, E. J. \& Bonsall, M. B. 2000: Enemy-mediated apparent competition: empirical patterns and the evidence. - Oikos 88: 380-394.

Connell, S. D. 2000: Is there safety in numbers for prey? Oikos 88: 527-532.

Connell, S. D. \& Gillanders, B. M. 1997: Mortality and abundance of a schooling reef fish. - In: Lessios, H. A. \& Macintyre, I. G. (eds.), Proceedings of the 8 th International Coral Reef Symposium, vol. 1: 1035-1038. Smithsonian Tropical Research Institute, Panama.

de Mazancourt, C. \& Dieckmann, U. 2004: Trade-off geometries and frequency-dependent selection. American Naturalist 164: 765-778.

Distel, R. A., Laca, E. A., Griggs, E. A. \& Demment, M. W. 1995: Patch selection by cattle: maximization of intake rate in horizontally heterogeneous pastures. - Applied Animal Behaviour Science 45: 11-21.

Dumont, B., Maillard, J. F. \& Petit, M. 2000: The effect of the spatioal distribution of plant species within the sward on the searching success of sheep when grazing. Grass and Forage Science 55: 138-145.

Ericsson, G., Edenius, L. \& Sundström, D. 2001: Factors affecting browsing by moose (Alces alces L.) on European aspen (Populus tremula L.) in a managed boreal landscape. - Écoscience 8: 344-349.

Hay, M. E. 1986: Associational plant defences and the maintenance of species diversity: turning competitors into accomplices. - American Naturalist 128: 617-641.

Hambäck, P. A., Ågren, J. \& Ericson, L. 2000: Associational resistance: insect damage to purple loosestrife in thickets of sweet gale. - Ecology 81: 1784-1794.

Herrera, C. M., Jordano, P., Guitián, J. \& Traveset, A. 1998: Annual variability in seed production by woody plants and the masting concept: reassessment of principles and relationship to pollination and seed dispersal. - American Naturalist 152: 576-596.

Hjältén, J., Danell, K. \& Lundberg, P. 1993: Herbivore avoidance by association: vole and hare utilization of woody plants. - Oikos 68: 125-131.

Holt, R. E. 1977: Predation, apparent competition and the structure of prey communities. - Theoretical Population Biology 12: 197-229.

Huhta, A.-P., Lennartson, T., Tuomi, J., Rautio, P. \& Laine, K. 2000: Tolerance of Gentianella campestris in relation to damage intensity: an interplay between apical dominance and herbivory. - Evolutionary Ecology 14: 373-392

Hunter, A. F. \& Aarssen, L. W. 1988: Plants helping plants. - BioScience 38: 34-40.

Ihalainen, E., Lindström, L. \& Mappes, J. 2007: Investigating Müllerian mimicry: predator learning and variation in prey defences. - Journal of Evolutionary Biology 20: 780-791.

Janzen, D. 1971: Seed predation by animals. - Annual Review of Ecology and Systematics 2: 465-492.

Järemo, J., Tuomi, J. \& Nilsson, P. 1999: Adaptive status of localized and systemic defense responses in plants. In: Tollrian, R. \& Harvell, C. D. (eds.), The ecology and evolution of inducible defenses: 33-44. Princeton Univ. Press, New Jersey.

Karban, R. 1997: Neighbourhood affects a plant's risk of herbivory and subsequent success. - Ecological Entomology 22: 433-439.

Karban, R., Brody, A. K. \& Schnathorst, W. C. 1989: Crowding and a plant's ability to defend itself against herbivores and diseases. - American Naturalist 134: 749-760.

Karez, R., Engelbert, S. \& Sommer, U. 2000: 'Co-consumption' and 'protective coating': two new proposed effect of epiphytes on their macroalgal host in mesograzerepiphyte-host interactions. - Marine Ecology Progress Series 205: 85-93.

Kobayashi, Y. \& Yamamura, N. 2003: Evolution of signal emission by non-infected plants growing near infested plants to avoid future risk. - Journal of Theoretical Biology 223: 489-503.

Kobayashi, Y. \& Yamamura, N. 2007: Evolution of signal emission by uninfested plants to help nearby infested plants. - Evolutionary Ecology 21: 281-294.

Leimar, O. \& Tuomi, J. 1998: Synergistic selection and graded traits. - Evolutionary Ecology 12: 59-71.

Mappes, J., Tuomi, J. \& Alatalo, R. 1999: Do palatable prey benefit from aposematic neighbors? - Ecoscience 6: 159-162.

Maynard Smith, J. 1988: Origin of social behaviour. In: Fabian, A. C. (ed.), Origins: The Darwin College Lectures: 115-127. Cambridge University Press, Cambridge, UK.

Maynard Smith, J. 1998: Evolutionary genetics, 2nd ed. Oxford University Press, New York.

McNaughton, S. J. 1978: Serengeti ungulates: feeding selectivity influences the effectiveness of plant defence guilds. - Science 199: 806-807.

Milchunas, D. G. \& Noy-Meir, I. 2002: Grazing refuges, external avoidance of herbivory and plant diversity. Oikos 99: 113-130.

Miranda, M., Díaz, L., Sicilia, M., Cristóbal, I. \& Cassinello, J. 2011: Seasonality and edge effect determine herbivory risk according to different plant association models. Plant Biology 13: 160-168.

Olff, H., Vera, F. W. M., Bokdam, J., Bakker, E. S., Gleichman, J. M., de Mayer, K. \& Smit, R. 1999: Shifting mosaics in grazed woodlands driven by the alternation of plant facilitation and competition. - Plant Biology 1: 127-137. 
O’Reilly-Wapstra, J. M., McArthur, C. \& Potts, B. M. 2004: Linking plant genotype, plant defensive chemistry and mammal browsing in a Eucalyptus species. - Functional Ecology 18: 677-684.

Palo, R. T. \& Robbins, C. T. 1991: Plant defences against mammalian herbivory. - CRC Press, Boca Raton.

Pfister, C. A. \& Hay, M. E. 1988: Associational plant refuges: convergent patterns in marine and terrestrial communities result from differing mechanisms. - Oecologia 77 : $118-129$.

Rand, T. A. 2003: Herbivore-mediated apparent competition between two salt marsh forbs. - Ecology 84: 1517-1526.

Rautio, P., Kesti, K., Bergvall, U. A., Tuomi, J. \& Leimar, O. 2008: Spatial scales of foraging in fallow deer: implications for associational effects in plant defences. - Acta Oecologia 34: 12-20.

Rhoades, D. F. 1979: Evolution of chemical defence against herbivores. - In: Rosenthal, G. A. \& Janzen, D. H. (eds.), Herbivores: Their interaction with secondary plant metabolites: 2-54. Academic Press, Orlando.

Schnurr, J. L., Ostfeld, R. S. \& Canham, C. D. 2002: Direct and indirect effects of masting on rodent populations and tree seed survival. - Oikos 96: 402-410.

Speed, M. P., Alderson, N. J., Hardman, C. \& Ruxton, G. D. 2000: Testing Müllerian mimicry: an experiment with wild birds. - Proceedings of Royal Society of London B 267: 725-731.

Svennungsen, T. O. \& Hole, O. H. 2007: The evolutionary stability of automimicry. - Proceedings of the Royal
Society of London B 274: 2055-2062.

Tahvanainen, J. O. \& Root, R. B. 1972: The influence of vegetational diversity on the population ecology and a specialized herbivore, Phyllotreta cruciferae (Coleoptera: Crysomelidae). - Oecologia 10: 321-346.

Thomas, C. D. 1986: Butterfly larvae reduce host plant survival in vicinity of alternative host species. - Oecologia 70: 113-117.

Tuomi, J. \& Augner, M. 1993: Synergistic selection of unpalatability in plants. - Evolution 47: 668-672.

Tuomi, J., Augner, M. \& Nilsson, P. 1994: A dilemma of plant defences: Is it really worth killing the herbivore? - Journal of Theoretical Biology 170: 427-430.

Tuomi, J., Augner, M. \& Leimar, O. 1999: Fitness interactions among plants: optimal defence and evolutionary game theory. - In: Vuorisalo, T. O. \& Mutikainen, P. K. (eds.), Life history evolution in plants: 63-83. Kluwer Academic Publishers, Dordrecht, The Netherlands.

Tuomi, J., Augner, M. \& Nilsson, P. 1996: On neighbour effects in plant-herbivore interactions. - In: Mattson, W. J., Niemelä, P. \& Rousi, M. (eds.), Dynamics offorest herbivory: quest for pattern and principle: $28-38$. General Technical Report NC-183, USDA Forest Service.

Wahl, M. \& Hay, M. E. 1995: Associational resistance and shared doom: effects of epibiosis on herbivory. - Oecologia 102: 329-340.

Vourc'h, G., Bila, B., Gillon, D., Escarré, J., Guibal, F., Fritz, H., Clausen, T. P. \& Martin, J.-L. 2002: Disentangling the causes of damage variation by deer browsing on young Thuja plicata. - Oikos 98: 271-283. 